\title{
LA IMAGEN URBANA DE SANTIAGO DE COMPOSTELA (ESPAÑA), UN ESTUDIO DE SU REPRESENTACIÓN PÚBLICA, MEDIÁTICA, PROMOCIONAL Y ARTISSTICA*
}

\author{
Luis Alfonso Escudero Gómez \\ Departamento de Geografía y Ordenación del Territorio. Universidad de Castilla-La Mancha \\ luisalfonso.escudero@uclm.es
}

\section{RESUMEN}

Santiago de Compostela, una pequeña ciudad periférica del Noroeste de España, es uno de los principales destinos turísticos del continente europeo. Las estrategias de promoción urbana y de creación de una imagen de capital cultural e histórica han logrado este éxito. Desde el último cuarto del siglo XX, las administraciones y agentes urbanos privados han construido una fuerte imagen pública a través de la idea del Camino de Santiago y de los Años Xacobeos. Cuando hemos finalizado uno de estos eventos, el de 2010, conviene analizar como en la prensa, en Internet, en las campañas promocionales públicas y privadas, en las iniciativas culturales, en las guías turísticas, en la obra de los artistas y en la literatura se refleja esta particular visión de Santiago de Compostela. Una imagen hecha a través de su Patrimonio, de su historia y de su funcionalidad cultural y turística. A cambio, la realidad social y los espacios de vida ciudadanos compostelanos desaparecen de su representación pública.

Palabras clave: Imagen, Promoción Urbana, Santiago de Compostela.

Fecha de recepción: octubre 2011.

Fecha de aceptación: enero 2013.

* Este artículo es resultado del proyecto Sistema de indicadores para el análisis de las dinámicas urbanas y metropolitanas en España a comienzos del siglo XXI, subvencionado por el Subprograma de Proyectos de Investigación Fundamental no orientada del Ministerio de Ciencia e Innovación con referencia CS02010-16298, 2/7/2010. 


\section{ABSTRACT}

Santiago de Compostela, a small peripheral city in North-western Spain, is one of the major tourist destinations in Europe. The strategies of urban marketing and an image of cultural and historical capital have achieved this success. Since the last quarter of the twentieth century, governments and private urban agents have built a strong public image through the idea of the Way of Santiago and the Jacobean years. When we are finishing the lasts Jacobean year, the 2010, it should be analyzed this particular image of Santiago de Compostela in the press, in the Internet, in the public and private marketing campaigns, in the cultural initiatives, in the tourist guides, in the work of artists and in the literature. An image made through Santiago's heritage, its history and its cultural and tourist functionality. In exchange, the social reality disappears of the Compostela public representation.

Key words: Image, Urban Marketing, Santiago de Compostela.

\section{LA CIUDAD, UN ESPACIO SUBJETIVO}

En este primer apartado del artículo reflexionaremos sobre algunas cuestiones acerca del espacio urbano subjetivo, la creación de imagen y la enorme importancia de la misma en la sociedad actual. Nos acercaremos al marco teórico sobre una temática que para el geógrafo urbano ya no es una novedad sino una orientación que debe tener presente en sus investigaciones como es la cuestión de la imagen de la ciudad. Asimismo, nos referimos brevemente a las fuentes que el investigador dispone para acercarse cualitativamente a la imagen pública de las ciudades y que serán las que posteriormente emplearemos para el estudio de caso de Santiago de Compostela.

\subsection{La imagen de la ciudad}

La apariencia real de una ciudad no coincide necesariamente con la percepción que tienen sus habitantes y sus visitantes. La capacidad de un núcleo urbano de proporcionar una imagen unitaria y sintética de sí mismo, que evoque algo importante, es fundamental (Amendola, 2000 , p. 289). Una ciudad se desarrolla en un espacio físico, pero también se constituye en un objeto multimedia, imagen, sonido y texto, y en un espacio de vida para los ciudadanos y foráneos. La imagen posee para el investigador urbano el papel de filtro que se interpone entre el hombre y el medio, y una de sus preocupaciones debe ser analizar esa imagen y comparar su parecido con el mundo real. Un proceso de vital importancia desde el momento en el que la toma de decisiones que afectan al medio no se efectúa sobre el espacio real sino sobre la imagen que el individuo tiene de él. En tanto en cuanto esa imagen se acerque o se aleje de la realidad, las decisiones serán tanto más coherentes y razonables (Ponce et al., 1994).

El espacio subjetivo en Geografía nos permite añadir nuevas facetas de la temática a estudiar, enriqueciendo y profundizando en la auténtica realidad cotidiana de los seres humanos (Boira, 1992, p. 581). La ciudad no es solo una realidad objetiva formada por el paisaje, las funciones urbanas y las características de la población; sino que fundamentalmente es un 
espacio vivido, sentido, valorado y percibido de forma diferente por los individuos, a través de representaciones mentales y de impresiones individuales y colectivas. La imagen urbana tiene, de este modo, un carácter simbólico, es algo más que el simple espacio; es, ante todo, la expresión visible de un sistema de valores del ser humano unido a sus creencias, ideales y esperanzas (Estébanez, 1982).

La percepción urbana sería una función psíquica que permite al individuo a través de los sentidos recibir, elaborar y organizar las informaciones provenientes del medio urbano (Zoido et al., 2000, p. 264). En este proceso perceptivo de aprehensión de la realidad, el sujeto tiene en un primer momento una reacción puramente biológica, pero como ser pensante dotado de memoria, esa información recibe una significación y un valor en relación con su personalidad profunda y su medio cultural, social y económico. A continuación, de ese mecanismo solo subsiste una imagen residual que la persona transforma en un modelo simplificado de la realidad, en el que se apoya para enjuiciar, valorar, decidir y actuar en la ciudad (Ibíd., p. 265). Las imágenes determinan el significado y simbolismo de las distintas partes de la ciudad; condicionan la actuación de los ciudadanos ante cuestiones concretas. La imagen, como concepto y condensación del significado que un lugar adquiere en su progresión, restringe la complejidad del mundo real y la ordena sirviéndose de determinados conceptos simbólicos. Es, por lo tanto, marco de comprensión y de referencia, un sistema de valores que determina los modelos de conducta y de comportamiento de las personas (Gil, 1994).

La imagen es un soporte de la comunicación visual en el que se materializa un fragmento del universo perceptivo, y que presenta la característica de prolongar su existencia en el curso del tiempo (Zunzunegui, 1989). Las imágenes mentales determinan, en la conducta reactiva, las manifestaciones verbales, las expresiones motrices y las actitudes emocionales (Costa, 1992). Establecen en nosotros pautas de pensamiento y conducta. La imagen de la ciudad es una representación, apariencia o figura que puede generar una urbe o una parte cualquiera de la misma y se forma a partir de la percepción concreta o mediatizada de la realidad (Zoido et al., 2000, p. 191). Hoy vivimos en un mundo mediático en el cual domina no tanto y no solo la ciudad sino más bien su imagen. Esta precede a la ciudad y media en la relación que tienen con ella las personas, tanto viajeros como ciudadanos (Amendola, 2000, p. 167).

Los espacios cognitivos son diferentes para cada uno de nosotros, pero una parte de esta realidad es compartida por un grupo de población, aquel que posea unas características comunes (unos filtros socioculturales). Se construye así una imagen pública que, para el caso que nos ocupa, un núcleo urbano, representa el conjunto de calidades, símbolos y caracteres asociados a una ciudad y compartidos por la mayoría de sus habitantes (Boira, 1992b). Esta imagen pública atribuye un significado a la ciudad, reduce la gran cantidad de información que los actuales ambientes urbanos proporcionan, crea una conciencia urbana compartida por la mayoría de los ciudadanos y perpetúa una serie de valores relacionados con la tradición, la historia y el orden dentro de la ciudad. Se trata de una imagen socialmente impuesta, colectivamente aceptada o, por lo menos, generalmente tolerada (Ibíd.).

La imagen pública está compartida por un gran número de individuos a los cuales llamamos el público. En la actual sociedad del consumo, resulta fundamental esta representación pública (Lyon, 1997). Además, la imagen de la ciudad es utilizada por los poderes institucionales y los agentes urbanos privados para desarrollar estrategias concretas de promoción, 
realzar algunos aspectos de su patrimonio y contrarrestar posibles lecturas negativas de la realidad urbana. Se trata de un uso propagandístico de ciertos símbolos o sensaciones positivas que evoca la ciudad, o cualquier área o lugar concreto, y que responde a actuaciones bien calculadas que tratan de influir sobre la opinión pública (Zoido et al., 2000, p. 191). Esta utilización se generaliza en la sociedad actual mediante un proceso continuo de creación de imagen, en el cual son fundamentales los medios de comunicación de masas que condicionan dicha opinión pública.

Una representación subjetiva de la ciudad, su imagen, es el primer factor actual de la producción urbana. Así, una cuestión principal para cualquier núcleo urbano es la construcción social de la imagen, un factor de designación y de asimilación de la realidad espacial, y de una identidad. Las ciudades ponen mucho cuidado en crear una imagen del lugar positiva y calificada (Harvey, 1998, pp. 112-113). Algo común, en realidad, en todos los ámbitos de nuestra sociedad, en especial en las órbitas de la representación social. Los poderes tienden a alimentar su imagen, en un mundo cada vez más respetuoso con la simbología de las apariencias, en el cual una buena imagen es signo y parte del poder (Moncada, 1991). En los diversos agentes urbanos proliferan los departamentos de relaciones públicas, gabinetes de prensa o similar, tanto al servicio de instituciones públicas como privadas. La creación de imagen se convierte en una cuestión profesional, llevada a cabo por agencias de publicidad y empresas de relaciones públicas. La ciudad es consciente de poder crear y recrear su imagen recurriendo, de manera plausible, a un repertorio prácticamente inagotable de símbolos, experiencias, representaciones, estilos y modas (Amendola, 2000, p. 174). En este contexto, todas las ciudades, con mayor o menor intensidad, desarrollan campañas de potenciación de su imagen bien, por ejemplo, como centros de cultura, bien como lugares de celebración de un gran acontecimiento de repercusión internacional o, simplemente, intentando difundir la idea de que en la ciudad se puede vivir aceptablemente y aprovechar el creciente tiempo reservado al ocio (Lois, 1999, pp. 506-07). De hecho, como consecuencia de la pugna que determina la dinámica económica actual, todas las ciudades tratan de conseguir transmitir su imagen más positiva, una imagen de marca. Una marca que sea capaz de generar la identificación de los ciudadanos con su urbe y, a la vez, de identificar también todo lo que se produce en la ciudad y que se pone en el mercado con su nombre (Benach, 2000, p. 194).

En las páginas siguientes trataremos la representación subjetiva de Santiago de Compostela, la construcción de una imagen pública que ha convertido a un pequeño núcleo gallego periférico en uno de los principales destinos turísticos del continente europeo. Por lo tanto, se trata de un caso de análisis para las cuestiones de imagen urbana de especial interés; para realizarlo acudiremos a diferentes fuentes que usaremos cualitativamente, por esta razón conviene presentarlas anteriormente

\subsection{El estudio de la imagen urbana a través del uso cualitativo de las fuentes}

En las últimas décadas se han ido introduciendo en la Geografía métodos y técnicas de análisis cualitativas, y lo mismo ha sucedido en realidad en todas las Ciencias Sociales. Se han desarrollado para comprender el significado subjetivo de los lugares, en nuestro caso de las ciudades. Las fuentes principales son los discursos formalizados de tipo lingüístico o iconográfico y las encuestas (Boira, 1996). En síntesis son el discurso escrito (desde la 
novela o la poesía a los libros de viajes, de los panfletos a los ensayos, de los viejos manuales a las más recientes publicaciones), el análisis de la imagen (dibujos, publicidad, fotografías, folletos turísticos), el estudio de los mapas mentales (cartografía subjetiva de un espacio concreto) y las encuestas y entrevistas (Ibíd.). Gil de Arriba (1994) en su tesis sobre la imagen de la ciudad de Santander utiliza estas fuentes (en su caso guías, obras literarias, artículos de prensa y libros divulgativos de tema regional y local) como medios generadores y difusores de significado. Nosotros estudiaremos el espacio subjetivo de Santiago de Compostela a través de muchas de estas fuentes, acercándonos sucesivamente a la imagen mediática, promocional y artística de la urbe. Finalmente, obtendremos la imagen pública de esta ciudad constatando como la literatura nos ilustra sobre el desarrollo y conformación histórica de la imagen pública del espacio mientras que la propaganda turística y la prensa nos informan del éxito de su transmisión.

En general, los medios de comunicación de masas contribuyen a configurar la imagen de los distintos lugares, es decir, a difundir representaciones que producen significado (Hernández, 2004, p. 1). Dentro de ellos, una de las principales fuentes para el estudio subjetivo de la ciudad es la prensa diaria. Actúa como fuente de construcción de la imagen de la ciudad. Este medio de comunicación juega un papel importantísimo no solo en la transmisión de noticias sobre espacios alejados, sino también en la creación de las condiciones (sentimientos, valoraciones, evaluaciones, preferencias) que permiten o, por el contrario, inhiben la experiencia del lector sobre un determinado espacio. Otros medios de comunicación, por su estructura organizativa, no cuentan con un papel tan privilegiado como portavoces de las noticias locales y son los diarios los responsables de conducir al lector a los propios espacios urbanos de su ciudad (Boira y Crespo, 1989, pp. 170-171; Gomis, 1991). De esta forma, mediante el análisis y la clasificación de las noticias aparecidas en los periódicos locales durante un periodo de tiempo determinado se puede descubrir la imagen externa que se proyecta de una ciudad y de sus barrios (Van Dijk, 1990, p. 225; Escudero Gómez, 1997 y 2000). Así lo han hecho diferentes autores como, solo por poner algún ejemplo, Gil de Arriba para Santander (2002), Paül (2007) para Barcelona y a través del evento del Fòrum o Tudurí (1998) para Palma de Mallorca.

Internet es otra fuente esencial en la actualidad para estudiar la imagen pública de un núcleo urbano. La website de una ciudad ofrece importantes oportunidades para su promoción. Los usuarios pueden acceder desde cualquier lugar y en cualquier momento a la información que nos proporciona (Rivero y Serra, 2002, p. 31). En este ámbito, las administraciones y los agentes privados se han esforzado por disponer en sus páginas web una adecuada imagen promocional de la ciudad. En Internet las ciudades crean imagen a través de sus páginas web y se proyectan en el tiempo y el espacio, tal y como ha estudiado Lara (2002) para múltiples ciudades. Las investigaciones actuales incluso empiezan a recurrir al análisis de los blogs para estudiar la creación de imagen (Antón, 2011). Estas bitácoras cibernéticas simplemente se limitan a amplificar para un nuevo consumidor lo que ha sido generado para el público por medios tradicionales (Capón y García, 2004, p. 119).

Otra fuente que vamos a utilizar para analizar la imagen pública de Santiago son las publicaciones y estrategias de promoción de los diferentes agentes urbanos de la capital compostelana. Las publicaciones de estos organismos, sus textos y fotografías, nos proporcionan una imagen simbólica que se ofrece al exterior. Una representación consensuada respecto a 
un determinado estereotipo urbano. La imagen de la ciudad es una variable que hay que tener bajo control y manipular en tiempos brevísimos y, por lo tanto, lo que antaño se dejaba a viajeros y escritores, hoy es confiado a los hombres del marketing y de los media (Amendola, 1998, p. 293). De esta forma, las administraciones han visto que se pueden vender como si de automóviles o de ropa se tratase, por lo cual se promocionan a través de la publicidad y de las relaciones públicas intentando cambiar su propia imagen (Hall, 2000).

Una de las publicaciones utilizadas son los folletos de información turística, los cuales son una guía durante la visita en el destino y recuerdo del mismo (Molina, 2005, p. 264). Se trata de una sencilla herramienta que a través del diseño visual y la incorporación de estímulos fortalecen la imagen de los destinos, contribuyendo a crearla o mejorarla. Roy Lichtenstein llegó a afirmar que el Partenon, por ejemplo, era mucho más conocido por los anuncios de las agencias de viajes que por la contemplación in situ de esta memorable obra clásica (extraído de Sobrino, 2005, p. 45). El análisis de estas imágenes, en una muestra aleatoria, se ha utilizado para comparar los paisajes reales con los subjetivos en el estudio de Palma de Mallorca (Picornell et al., 2009). Las guías turísticas, con una información y extensión más amplia que los folletos, también responden al proceso de construcción social de la imagen de un lugar y contribuyen a consolidarlo y proyectarlo (Galí, 2005, p. 19). La ciudad de Girona ha sido estudiada a través de esta fuente cualitativa (Ibíd.).

La literatura es otra referencia fundamental para el análisis subjetivo de la ciudad. La literatura es una muestra existencial de una sociedad que, al no ser una fuente científica, debe ser interpretada por el investigador (Campillo, 1989). Sus paisajes artificiales tienen la ventaja de comunicar imágenes coherentes y con un determinado sentido proporcionado por la visión perceptiva del artista y de su capacidad para captar las sensaciones que nos quiere transmitir (García Ballesteros, 1992). Analizando los textos literarios existentes de una ciudad descubrimos la imagen urbana que se ha ido conformando a lo largo de su historia y así se ha realizado en numerosos ejemplos en la geografía española, incluso llegando a utilizar hasta el cómic como fuente literaria cualitativa (Cejudo et al., 2005). La propia promoción urbana ha sabido aprovechar la fuerza de la imagen literaria para crear rutas y eventos turísticos como el conocido Bloomsday que anualmente conmemora en Dublín el 16 de junio, que es cuando transcurre la acción del Ulises de James Joyce, recreando la novela a través de los escenarios de la ciudad; o como hizo Sevilla en el momento de mayor éxito de la novela La Piel del Tambor de Pérez Reverte con una ruta literaria a través de 24 establecimientos relacionados con la narración.

$\mathrm{Al}$ igual que los textos literarios, el cine es otra interesante fuente cualitativa para descubrir la imagen pública de una ciudad. En las películas las ciudades aparecen como escenario, retrato de paisaje, fondo sobre el que transcurre la acción, o como ambiente, protagonista, referencia psicológica o utopía (Zárate, 1995, p. 262). Incluso, hay una técnica cinematográfica, el stablishing shot, que consiste en insertar enclaves o hitos que sirven de transición entre una escena y la siguiente (Gámir y Valdés, 2007, p. 170); paisajes o postales que elaboran una imagen subliminal en el espectador. De este modo, la imagen cinematográfica, lo mismo que la literaria, nos sirve para conocer, comprender y analizar el espacio urbano subjetivo. Costa (2009) ha utilizado esta fuente cualitativa para el estudio de los paisajes urbanos. 
Otras expresiones artísticas también pueden ser utilizadas como fuente cualitativas para el estudio de la imagen urbana. De hecho, en ocasiones para análisis históricos son las únicas disponibles pues a lo largo del tiempo se ha ido representando la ciudad desde diferentes manifestaciones artísticas. Las ilustraciones de Las Cantigas de Alfonso X en el siglo XIII y los grabados realizados por Hoefnagel a mediados del siglo XVI para la obra de George Graun Civitatis Orbis Terrarum son dos ejemplos a añadir a innumerables retablos, lienzos, tablas, grabados, bajorrelieves, obras de orfebrería que fueron utilizados por Ayerbe, Feria y Joaquín en su Atlas de Andalucía (2000). Según estos autores, todas estas representaciones artísticas tienen algunas notas comunes: su idealización, su falta de objetividad y su deseo de dar a conocer una realidad (Ibíd., p. 18). Desde el Renacimiento, numerosas ciudades han proyectado su propia imagen en reproducciones, ante los ojos propios y de los forasteros, siendo un recurso publicitario de su grandeza (Braunfels, 1987, p. 98). Durante este dilatado periodo de tiempo, las ciudades fueron dibujadas, grabadas y esculpidas como ha estudiado Azúa (2004).

En definitiva, con estas fuentes que hemos presentado abordamos nuestro estudio de la imagen pública de Santiago de Compostela.

\section{LA IMAGEN MEDIÁTICA DE SANTIAGO DE COMPOSTELA}

La mayor parte de la imaginería actual procede de los medios de comunicación de masas, por lo cual su estudio es de gran utilidad para entender el espacio subjetivo de una ciudad. En nuestro acercamiento a la visión subjetiva de Santiago acudimos, en primer lugar, a esta imagen mediática, y lo haremos a través de dos experiencias diferentes. La primera centrada en el medio de comunicación de masas más vinculado con una ciudad, que cuenta con un claro poder establecido como agente urbano y que podemos calificar ya como tradicional: la prensa local. La segunda, mediante el medio más efervescente de la postmodernidad, realidad de nuestros tiempos: Internet. Para el medio de comunicación tradicional recurrimos al trabajo de la tesis doctoral del autor que ya abordaba a través de la prensa la imagen de Santiago de Compostela (junto con las dos otras ciudades principales de su provincia, A Coruña y Ferrol) (Escudero, 2000), y para el más reciente un pequeño ejercicio de exploración en la Web realizado en 2011 .

Comenzando por la prensa local, señalar que es uno de los principales impulsores de la imagen pública de una ciudad. En el año 2000 concluíamos un estudio sobre la imagen periodística de la ciudad de Santiago de Compostela aplicando una serie de indicadores y análisis sobre el tratamiento que los periódicos le otorgaban. El análisis hemerográfico de la ciudad estaba basado en las noticias publicadas por el periódico santiagués «El Correo Gallego»y por la edición compostelana del rotativo coruñés «La Voz de Galicia» durante un periodo de tiempo lo suficientemente significativo para extraer conclusiones: tres años completos de periódicos, entre 1993 y 95; analizando todas y cada una de las noticias relacionadas con la ciudad de Santiago.

En el periodo de nuestra investigación los dos periódicos publicaron un total de 35.730 noticias. Ambos dedicaron una cantidad bastante similar a Compostela, 17.948 «El Correo» y 17.782 «a Voz». Este elevado número de informaciones se distribuye, sin embargo, de una forma muy polarizada entre las áreas santiaguesas. Fundamentalmente, la diferencia se esta- 
blece entre el centro urbano de Santiago y el resto de la ciudad ya que los espacios centrales reúnen el 52,69\% de las noticias (un total de 18.829). El centro histórico de Santiago y el área denominada como Ensanche, los espacios urbanos compostelanos centrales, marcan el aspecto principal de la representación de la urbe y se destacan como sus espacios más significativos a nivel administrativo, social, religioso, turístico, patrimonial, de servicios, universitario, etcétera. La imagen de las áreas centrales fija la percepción global de la ciudad. Una concepción parcial y esquematizada de la realidad urbana que privilegia el centro y relega a los barrios periféricos.

Otra nota principal de la imagen periodística de esta ciudad es la utilización general de la cultura y del Patrimonio como elemento clave de su promoción. Santiago cuenta con un centro histórico de significado único que fue declarado Patrimonio de la Humanidad por la UNESCO y que se relaciona con una ruta de peregrinación religiosa de origen medieval y que hoy es un destino turístico de primer orden. Los periódicos participan decididamente en una intensa campaña de promoción y de creación de una imagen de Santiago asociada al significado del Camino (Fig. 1). Igualmente, la celebración de constantes actividades culturales y de ocio ocupa siempre un lugar de privilegio en los periódicos. De esta forma, la prensa local apoya todas las iniciativas oficiales para la promoción de la ciudad como capital cultural y patrimonial.

Figura 1

PORTADA DE UN SUPLEMENTO DEL DIARIO «LA VOZ DE GALICIA», 12-7-2010

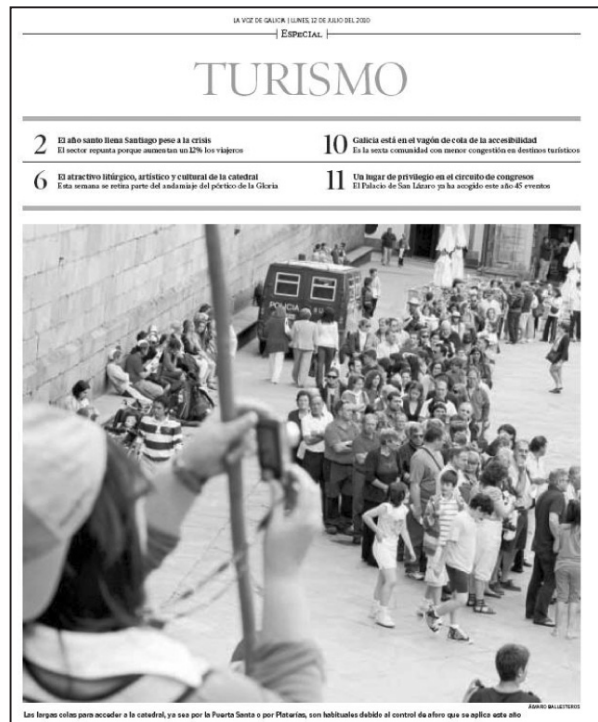

\section{El milagro del Apóstol}

Compostela es el destino turístico español que más crece este año gracias al Xacobeo

Se construye así en los medios de comunicación de masas una imagen de marca mediante la cual acceder al mercado. Una visión basada en la multifuncionalidad y el carácter histórico-cultural de la ciudad. Una imagen que parte de la realidad para moldearla y manipularla, 
y que acaba creando una representación subjetiva parcial, muy positiva y terciarizada. La recreación de la mejor imagen posible que sacrifica la realidad social, las condiciones de vida y la entropía urbana. Así lo refleja el análisis global de la valoración perceptiva de las informaciones de la prensa local. Por encima de la subjetividad de este indicador se obtienen diferencias significativas. El 71,63\% de todas las noticias publicadas, 25.592, podemos considerarlas como positivas. Frente a este elevado porcentaje, el 20,64\% de las noticias de la ciudad tienen contenidos negativos (7.374) y, finalmente, el 7,74\% restante, 2.764 artículos, son intermedios. La relación es, por lo tanto, ampliamente favorable hacia las informaciones de carácter positivo: un 70:20. Esta subjetivización positiva de la imagen periodística de Santiago es el resultado de una identificación entre la prensa y las administraciones y grupos de interés de la ciudad. En el artículo veremos que estos agentes urbanos trabajan en la promoción de Compostela con una imagen basada en su historicidad, su funcionalidad y sus atractivos turísticos (la misma que nos presentan los diarios).

Nuestra segunda investigación de la imagen mediática de Santiago, está basada en el medio de comunicación de masas de mayor crecimiento en la actualidad, Internet. En este medio también es común la construcción de promociones que identifiquen a las ciudades y las proyecten cara el futuro como ya se ha estudiado para núcleos como Almería, Burgos, Cáceres, Granada, A Coruña, Salamanca, Sevilla o Zaragoza (Lara, 2002) o bien para las ciudades de la Península Ibérica que son Patrimonio de la Humanidad (Escudero, 2007).

La profusión de información de Santiago de Compostela en la red de redes excede con mucho la capacidad de un usuario normal. Cualquier persona que acuda a Internet no abrirá toda las páginas disponibles sino que hará una selección, bien visitando unas Webs de las cuales tenga una noción previa bien, y esto es lo más normal, yendo a algún buscador que le haga el trabajo de delimitación y encuentro. El número de buscadores en la red también es elevado, pero entre ellos dos o tres concentran la mayor parte de servicios, y de estos destaca ostensiblemente el denominado google. En nuestra investigación, realizada en 2011, como si fuésemos un individuo anónimo que quisiera acercarse a la ciudad en Internet escribimos «Santiago de Compostela» en este motor de busca (google.es, 2011) y obtuvimos inmediatamente unas referencias entre las miles que el servicio nos informaba que existían. En concreto, diez páginas Webs principales son las que se nos ponían a disposición, además de apartados de localización, noticias e imágenes. Limitamos nuestro muestreo a estas 10 primeras Webs que nos ofrece google en su página principal porque serían estas las que mayoritariamente consultarían los internautas y para nuestro estudio de esta fuente lo consideramos suficiente. Estas páginas principales son las que se encargaban de representar al término «Santiago de Compostela» en la red global para aquel que quisiera conectarse, ya sea en la propia ciudad o en sus antípodas. Merece la pena empezar por las propias fotografías que google nos sugiere para Santiago de Compostela (Fig. 2). La inmensa mayoría son representaciones de la Catedral de Santiago, y las pocas que no, imágenes del centro histórico. Básicamente la postal de Internet de Compostela, su identificación, es el hito de la Catedral.

La primera Web que aparece en 2011 en el buscador google es la del Ayuntamiento de Santiago (santiagodecompostela.org, 2011). Accediendo a ella, en portada sobresale una imagen de la Catedral de Santiago y la celebración de su 800 aniversario (el 2011 es un año posterior al Xacobeo de 2010 -y no habrá un próximo Año Santo hasta 2021- pero la ciudad y su municipio ya han buscado un evento para rellenar su hueco, dado que el 21 de abril de 
1211 el obispo Pedro Muñiz consagraba solemnemente esta catedral) y el logotipo del Ayuntamiento, que es un anagrama con la forma de la Catedral. Los símbolos que la administración local adopta son los más estereotipados.

Figura 2

IMÁGENES DE LA PÁGINA PRINCIPAL DE GOOGLE TRAS LA BÚSQUEDA DE «SANTIAGO DE COMPOSTELA»

\section{Imágenes de "Santiago de Compostela" - Informar sobre las imágenes}
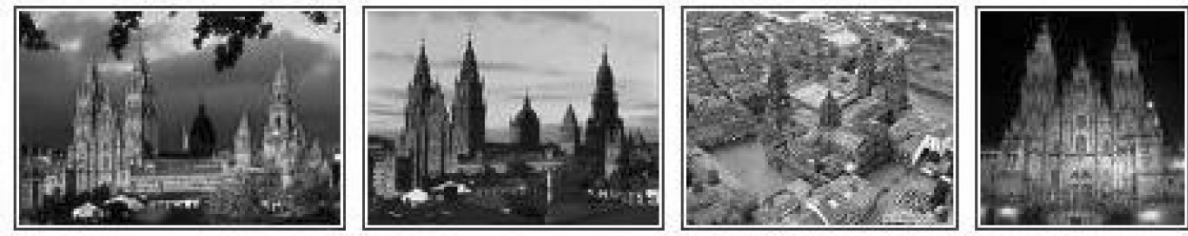

Fuente: google.es, 2011.

La segunda página que aparece es la entrada de Santiago de Compostela en la Wikipedia. Todos conocemos la poca fiabilidad de esta fuente, y así se lo recomendamos a nuestros alumnos, pero también sabemos del poder de difusión que ha logrado la misma. Por esta razón, veamos cómo se define Compostela aquí: En ella tiene su sede el gobierno autónomo gallego (Junta de Galicia) y el Parlamento. Destaca por ser un importante núcleo de peregrinación cristiana, junto con Jerusalén y Roma, al señalar la tradición de que allí se dio sepultura al Apóstol Santiago el Mayor. De especial importancia artística es su Catedral dedicada precisamente al Apóstol Santiago el Mayor. Es también relevante su Universidad, de más de 500 años de historia (es.wikipedia.org/wiki/Santiago_de_Compostela,2011). Por lo menos, se hace referencia a dos funciones urbanas importantes de la ciudad, aparte de la cita a la Catedral, la política y la universitaria. No obstante, las imágenes que ilustran esta entrada vuelven a hacer referencias históricas, del casco antiguo y, sobre todo, de la Catedral (incluyendo una con un grupo de gaiteros en su puerta de Platerías en una representación folk kitsch totalmente inefable). La tercera Web es una guía turística, Compostela Virtual (compostelavirtual.com, 2011). Una Web no oficial, privada y con un carácter claramente lucrativo (la cual probablemente haya pagado por estar en un lugar tan preferencial en el buscador universal), pero que se abastece también del Patrimonio y la historia para crear el estereotipo de Compostela y la fotografía de la Catedral es la más profusa de la página (en medio de la venta de hoteles, restaurantes y demás servicios turísticos).

La cuarta página que aparece en realidad no participa de esta construcción de imagen salvo por la referencia a la función educativa de la ciudad, pues se trata de la Web de la Universidad de Santiago (usc.es, 2011). Los centros universitarios fueron los primeros en utilizar la red Internet y siguen potenciando este medio de comunicación fuertemente. La siguiente página también es una Web privada de promoción turística que forma parte de una serie denominada Todo sobre España (red2000.com/spain/santiago/1 santia.html, 2011). Entre anuncios de hoteles y restaurantes, e ilustrado con la foto de la Catedral desde la Alameda de Santiago, podemos leer la siguiente narración repleta de los tópicos que forman la imagen pública de Compostela: llegamos a Santiago de Compostela con una lluvia suave para la que no fue necesario usar 
el paraguas, y al mediodía nos encontramos con un sol espléndido en la plaza del Obradoiro, corazón impresionante de la ciudad, aglomerada con miles de turistas y personas del lugar. Con grandilocuencia hispana se trata todo lo relativo al apóstol.

Después de tanta referencia al hito por excelencia compostelano, resulta que la sexta página es precisamente la oficial de la Catedral (catedraldesantiago.es, 2011). En ella una presentación multimedia difunde a este hito por la red y lo asocia definitivamente con Santiago. A continuación, aparece otra Web privada de promoción y servicios turísticos, la de Galinor (galinor.es/Santiago, 2011) y las imágenes son las mismas: el Apóstol y la Catedral. Entre las informaciones dedicadas a los hipotéticos visitantes de la ciudad (hoteles, monumentos, restaurantes... y referencias al Camino) en su portada se inserta una breve sinopsis histórica. Las primeras frases de la misma son suficientemente evocadoras del estereotipo construido: en los primeros años del siglo IX el obispo de Iria, Teodomiro, descubre el sepulcro del Apóstol Santiago. Los reyes Alfonso II y Alfonso III levantan iglesias y fundan los monasterios de Antealtares y Pinario. El culto a Santiago hace recelar a Almanzor que en el 997 arrasa e incendia Compostela llevándose a Córdoba las campanas. Más tarde la peregrinación llega a su auge y Alfonso VI inicia la catedral románica en el 1075 (Ibíd.).

Posteriormente, volvemos a obtener una página institucional, la del Arzobispado de Santiago (archicompostela.org, 2011), aunque con un significado obviamente más religioso, la imagen de la Catedral vuelve a ser la referencia. Luego, otra Web turística privada, la de Costasur (santiago-de-compostela.costasur.com, 2011) que no varía un ápice lo descrito para sus homónimas anteriores y, finalmente, la última página que aparece es la de la Cámara de Comercio de Santiago. Aquí, la información económica, acorde a las funciones de este organismo, prevalece en la Web. No obstante, en medio de noticas y enlaces empresariales y comerciales aparece uno destinado a los caminos Xacobeos y otro a la tarjeta de crédito de la Cámara cuyo fondo, ¿no lo adivinan?, es la Catedral compostelana.

En conclusión, hemos comprobado que, desde diferentes ámbitos, a través de páginas oficiales y privadas, la imagen en Internet de Santiago de Compostela es muy similar a la periodística. Así, se hace un uso constante de hitos como la Catedral, de referencias a la cultura y el ocio, de imágenes del centro histórico y de informaciones de la funcionalidad terciaria de la urbe.

\section{LA IMAGEN PROMOCIONAL DE SANTIAGO DE COMPOSTELA}

Los medios de comunicación de masas elaboran una imagen parcial de Santiago de Compostela basada en sus funciones urbanas más estratégicas y en un estereotipo de capital cultural y turística. Una representación que se relaciona directamente con el esfuerzo promocional que diferentes agentes urbanos, públicos y privados, realizan para colocar a Santiago en un lugar de preferencia en la competencia urbana, muy presente entre las ciudades con centros históricos ricos en patrimonio cultural (Campesino, 2000). De hecho, esta ciudad destaca entre las ciudades gallegas y españolas por la especial atención que sus autoridades prestan a la construcción de una imagen de marca que sea capaz de atraer. Además de los propios medios de comunicación, múltiples instrumentos del marketing urbano son empleados para la promoción de Santiago y la creación de una imagen pública: publicaciones turísticas, campañas publicitarias, guías de viaje y diversas actividades promocionales. 


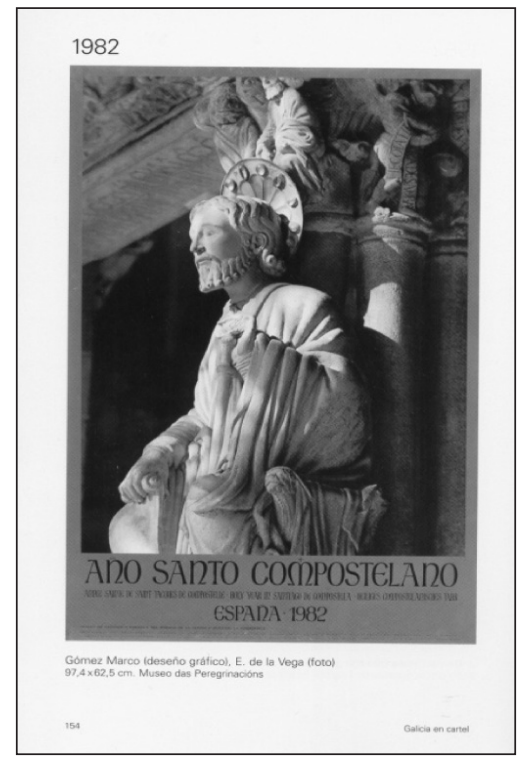

Fuente: Santos, 2002, p. 154.

La imagen promocional es una selección premeditada y concreta del conjunto de imágenes de la ciudad (Galí, 2005, p. 19). En la construcción de la marca urbana Compostela un elemento sobresale sobre cualquier otro como eje fundamental de promoción de la ciudad: el Camino y su meta Santiago. A su alrededor se produce en los últimos años una modélica actuación de imagen que se traduce en uno de los principales recursos turísticos de Galicia y en una identificación de la ciudad que gira en torno al significado cultural y de ocio del Camino. Asociado al Camino de Santiago se desarrolla el uso de la cultura como promoción urbana (mediante una constante celebración de actividades) y se defienden los valores estéticos y arquitectónicos que conserva el centro histórico compostelano.

La recuperación más o menos forzada de lo que fue un camino de peregrinación europea en la época medieval ${ }^{1}$ llega a su máximo nivel, en esfuerzos económicos y publicitarios así como en el éxito obtenido, en la década de 1990 (aunque ya podemos situar el año 1982 como precedente, tal y como vemos en el cartel institucional de la Fig. 3, con el mismo icono recurrente del Apóstol) y se sigue manteniendo hoy. En concreto, fue fundamental la reconversión del Camino de Santiago en ruta turística del final del Milenio, puesta en marcha a partir del Año Xacobeo de 1993 y de 1999. Para tal fin, fue necesaria una intensa campaña de promoción y de creación de una imagen de Compostela asociada a la identidad de esta ruta y a la celebración de múltiples actividades culturales y de ocio hasta logra atraer, como se

1 En un reciente artículo, Alonso Otero (2009) hace un brillante análisis paisajístico de Santiago y los Caminos de Santiago. 
consiguió ya en 1993 y se refrendó en el último Xacobeo de 2010 (ver tabla nº 1), a cientos de miles de viajeros anuales españoles y extranjeros; un flujo turístico de pragmáticos beneficios económicos. La afluencia masiva de personas que recorren hoy el Camino en dirección a Santiago es fruto pues de esta intensa promoción y de las inversiones realizadas por las diferentes administraciones, principalmente el gobierno regional y el Ayuntamiento.

Tabla 1

VIAJEROS RECIBIDOS EN SANTIAGO DE COMPOSTELA EN EL AÑO XACOBEO 2010

\begin{tabular}{|l|c|c|c|}
\hline \multicolumn{1}{|c|}{$\mathbf{2 0 1 0}$} & Residentes en España & Residentes en el extranjero & Total \\
\hline Enero & 16.217 & 3.676 & 19.893 \\
\hline Febrero & 25.054 & 5.813 & 30.867 \\
\hline Marzo & 32.861 & 7.954 & 40.815 \\
\hline Abril & 25.751 & 18.802 & 44.553 \\
\hline Mayo & 40.442 & 29.231 & 69.673 \\
\hline Junio & 44.993 & 26.927 & 71.920 \\
\hline Julio & 45.850 & 33.017 & 78.867 \\
\hline Agosto & 63.222 & 33.895 & 97.117 \\
\hline Septiembre & 47.347 & 33.837 & 81.184 \\
\hline Octubre & 51.075 & 27.792 & 78.867 \\
\hline Noviembre & 37.128 & 9.174 & 46.302 \\
\hline Diciembre & 29.224 & 5.890 & 35.114 \\
\hline \multicolumn{1}{r|}{ Total } & 459.164 & 236.008 & $\mathbf{6 9 5 . 1 7 2}$ \\
\hline
\end{tabular}

Fuente: INE. Encuesta de ocupación hotelera (ige.eu, 2011).

El Camino, los años jubilares, la cultura y el turismo son claras identidades de la imagen promocional de Santiago de Compostela. Una marca urbana que coincide con una representación turística de la ciudad. Su reclamo principal es la atracción de visitantes, y fortalece la ruta y los Xacobeos como acontecimientos únicos e irrepetibles (aunque tengan una periodicidad evidente), repletos de estímulos. Con tal fin se emplean todos los componentes posibles: el significado religioso, la idea de aventura, la diversión, el ocio, la cultura, el patrimonio de la ciudad, la historia, la gastronomía, etcétera. Podríamos hacer un catálogo o un simple repaso de las diversas y numerosas medidas promocionales asociadas a la imagen de Santiago y del Xacobeo y nos saldrían todas las enumeradas.

En el año 1991 se creó por parte de la administración autonómica la Sociedad Anónima de Gestión del Plan Xacobeo 93 como órgano ejecutivo de la promoción del Camino de Santiago y de Galicia en general. Las medidas del citado plan igualaban los fines materiales, como la recuperación y la rehabilitación física del Camino Francés a Santiago, que es el más utilizado (Alonso, 2009, p. 218), o la dotación de una red pública de albergues, con los promocionales y culturales. Se tenía en cuenta que en nuestra sociedad tan importante como el hacer es el vender una imagen de lo que se hace. Entre las medidas promocionales algunas 
son tan obvias como la creación de una mascota, el Pelegrín (ver Fig. 4); después abandonado, como le sucede a las mascotas de los acontecimientos deportivos, o de un logotipo, iconos que pasan a formar parte de la imagen urbana de Santiago y que fueron reproduciéndose constantemente desde en un cartón de leche hasta en la Vuelta Ciclista a España. Hoy, ya es el propio nombre de Xacobeo, como marca de la ciudad y del Camino, el que aparece en múltiples ámbitos, desde en ediciones de libros y en patrocinios de equipos deportivos de élite hasta en botellas de cerveza o cupones de la ONCE como el especial sobre el Camino de Santiago del 20 de abril de 2010.

La imagen promocional de Santiago se basa en una representación turística asociada al Camino, a la cultura y al Patrimonio. Se fundamenta el estereotipo de la ciudad en su función de urbe turística sobre otras posibilidades que, con cierta benevolencia a nuestro juicio, se pueden considerar como más seguras y, por ello, con menos necesidad de promoción. Es decir, la funcionalidad administrativa, universitaria o sanitaria de la ciudad, por ejemplo, se contemplan como caracteres propios e intrínsecos a ella (aunque en los últimos folletos turísticos de la ciudad empezamos a detectar la aparición de estas otras realidades como en el titulado A cidade escondida entre parques e xardíns, centrado en las áreas verdes compostelanas, las centrales y las periféricas, pero destinado realmente al ciudadano y al visitante gallego (está publicado en gallego) o en el titulado Santiago es grande (este en castellano), donde dedican de forma original un punto 3 (los dos anteriores son los habituales y ya descritos) a otros Santiagos, hablándonos del campus universitario y de los parques también).

Figura 4

PELEGRÍN, MASCOTA PROMOCIONAL DEL XACOBEO 1993, HOY JUBILADO

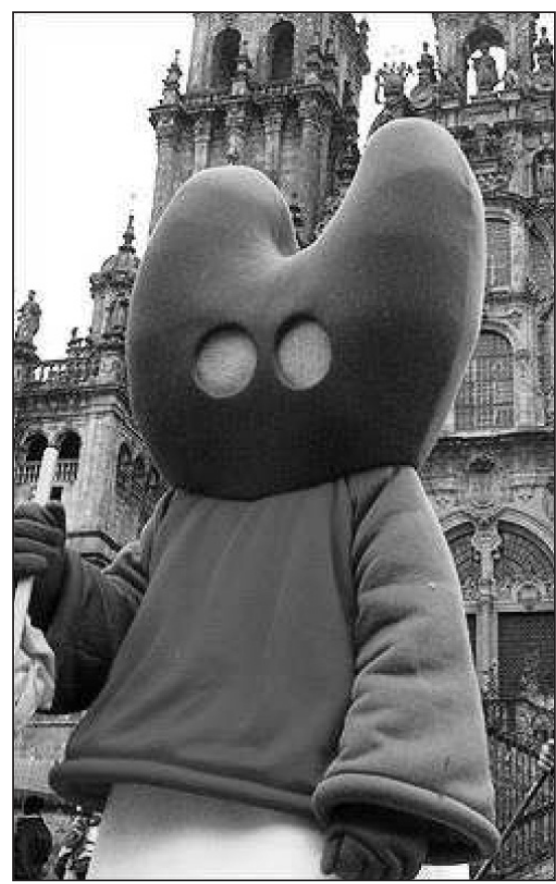


Las iniciativas se dirigen hacia el turismo cultural y a él se destinan las principales inversiones económicas y humanas. Sin embargo, recordemos que el turismo es un sector muy volátil, muy sensible a las variaciones de la moda y de los gustos. Si actualmente el turismo cultural, como el del Camino, demuestra ser una alternativa (especialmente para los centros históricos de las ciudades españolas como ha estudiado Troitiño -1995) para aprovechar nuestros periodos vacacionales de una manera distinta a la tradicional de sol y playa, nadie puede asegurar que en el futuro no surja una nueva clase de turismo que lo sustituya o que desaparezca la moda del Camino o, peor aún, que una crisis económica cambie nuestros tiempos y hábitos con respecto al ocio.

La representación turística, promocional, de Santiago es la percepción que también podemos obtener en una de las fuentes más tradicionales de creación de imagen urbana como son las guías turísticas. En esta nueva herramienta de delimitación subjetiva de una ciudad, Santiago de Compostela vuelve a destacar cuantitativamente. El número de publicaciones sobre Santiago y el Camino es enorme (en una investigación superficial pudimos calcular más de cincuenta guías diferentes). A veces la propia administración, como la Xunta de Galicia, dispone de gran cantidad de guías; otras veces estas guías aparecen dentro de los medios de comunicación de masas.

En las guías del Camino de Santiago, la vinculación de Compostela con su finalidad turística y patrimonial es muy evidente. Podemos poner algunos ejemplos entre las múltiples publicaciones existentes, como las obras de Anguita (2004), González (2004), Pombo (2004) o Nadal (2003). La primera, escrita por el presidente de la Asociación Gallega de Amigos del Camino, detalla las etapas de las diferentes rutas; la segunda, describe el Camino Francés, sus prolongaciones históricas y caminos alternativos con abundante información del contexto histórico y la riqueza patrimonial, en especial los referentes a Compostela; la tercera, se centra en el Camino Norte, con sus rutas e informaciones prácticas básicas, finalizando en Santiago; y la cuarta sobresale por el abundante uso de la infografía y de fotografías y por un atento cuidado en los datos prácticos. Por otro lado, también encontramos guías que añaden alguna particularidad a la tipología más habitual de esta literatura. Por ejemplo, la de Heréter (1998) nos presenta una visión aérea, una mirada diferente sobre el Camino y el Patrimonio del centro histórico de Santiago para reflejar la ya conocida imagen patrimonial de Compostela. Una idéntica visión nos la muestra la original obra de Bouzas y Domelo (2004). Estos autores, pese al significativo título de su libro (Santiago de Compostela. Y después del abrazo al santo, ¿qué? ), vuelven a recrearse en la leyenda y en el sentido de las peregrinaciones jacobeas para después recurrir a la riqueza patrimonial, cultural, gastronómica y festiva de Santiago de Compostela y la de Galicia para sellar una vez más el estereotipo de la capital gallega.

En las guías específicamente centradas en Santiago (y no en el Camino en general), encontramos una vez más la iconografía turística, la del centro histórico compostelano, y el recurso a la cultura. En realidad, no hay muchas diferencias entre las guías de la ciudad y las del Camino, en las primeras hallamos información de la ruta jacobea y viceversa. Analizamos brevemente una de estas guías de Santiago: la obra de Seixas (1998), un total de 446 páginas, de las cuales más de 200 se centran en el Camino (con un capítulo específico) y en el patrimonio histórico de la ciudad (destacando un profuso apartado sobre la Catedral); y esto teniendo en cuenta que una buena parte de la guía se dedica a Galicia en general. Poca 
información encontraremos, sin embargo, sobre otras funcionalidades urbanas de Santiago o sobre sus barrios periféricos. El lector de la guía asociará Santiago con su historia, arquitectura, museos, la Plaza del Obradoiro y las calles del centro histórico, la Catedral y el Camino. Estos son los hitos de la imagen turística de Santiago.

Un último ejemplo, en la obra de los geógrafos Formigo y Lois (2000) tenemos varios capítulos sobre itinerarios por la ciudad de Santiago (pp. 33-80). Cuatro son los recorridos que se nos proponen. Tres de ellos se desarrollan en el casco antiguo: la ciudad histórica sur, la norte y la visita al conjunto catedralicio. Una ruta exterior (pp. 73-80) complementa excepcionalmente una visión más amplia de Santiago, de su otra realidad, la que no forma parte de su imagen pública pero sí de su vida cotidiana, la que no es el destino de los esfuerzos promocionales ni interesa al visitante.

\section{LA IMAGEN ARTÍSTICA DE SANTIAGO DE COMPOSTELA}

En varias ocasiones hemos señalado ya a la cultura como un elemento constitutivo esencial de la promoción urbana de Santiago y hemos hablado de su fuerza para añadir connotaciones positivas a la percepción de la ciudad. De esta forma, tanto en la imagen mediática como en la promocional las actividades culturales son utilizadas como creadoras de una visión amable de Compostela, la de capital de la cultura. Entre sus virtudes, la cultura destaca por ser un instrumento que sirve para reforzar la identidad social, y por su poder de signo de prestigio (Lara, 2002, p. 420). Por esta razón, la cultura es una carta de presentación para la imagen de una ciudad. Saber cuál es la representación de una urbe que procede de la cultura resulta primordial, tanto por sus características como por su participación en la imagen pública de la ciudad. Desde el Arte proviene un porcentaje importante de la visión subjetiva de cualquier núcleo urbano. Aquellas ciudades que posean una figura artística fuertemente vinculada a ellas gozan de una poderosa representación urbana, pensemos en el Dublín de Joyce o en el Nueva York de Andy Warhol o Woody Allen, por poner dos ejemplos nada rebuscados. La mayoría de las urbes tienen a su particular escala una imagen artística que las define, unos autores de una u otra arte (nativos o foráneos) que, con su sensibilidad especial, saben percibir la ciudad y nos proporcionan unos espacios subjetivos más ricos. Por ese especial valor de la cultura y de la percepción de los artistas, la imagen pública de una ciudad se alimenta de la visión de estos autores y, en contrapartida, en sus obras podemos rastrear los rasgos del estereotipo de una ciudad.

Un núcleo urbano tan ligado desde su origen a la cultura y al arte como Santiago de Compostela, y hoy tan preocupado por la promoción urbana y la creación de una imagen de marca, lógicamente posee una rica percepción artística. A lo largo de su historia arquitectos, escultores, músicos, novelistas, cineastas, pintores, poetas... se inspiraron en Compostela, desarrollaron su obra en la ciudad o simplemente la percibieron de un modo peculiar y así lo reflejaron en su trabajo. De hecho, hacer un estudio en profundidad de la representación artística de la ciudad supondría repasar la Historia del Arte compostelana, su patrimonio de piedra, sus cuadros, sus esculturas y sus miles de publicaciones literarias diferentes. Nosotros no ambicionamos tal, queremos aprehender algo de la imagen artística de Santiago (como hicimos con la mediática y la promocional) y añadir sus caracteres más obvios dado que son consubstanciales a la imagen pública de la ciudad. Con este objetivo hemos realizado dos 
análisis. En el primero nos acercamos a la representación artística de Santiago aprovechando una exposición colectiva sobre Compostela. En el segundo, nos detendremos en la imagen literaria y cinematográfica de la urbe, con una selección personal y subjetiva (como todas las selecciones) de diferentes referencias.

La exposición «Compostela», organizada entre el 5 de marzo y el 30 de mayo de 2004 por el Centro Gallego de Arte Contemporánea en su sede santiaguesa, constituyó una oportunidad única para estudiar la imagen artística actual de la ciudad. Además de la visita en vivo, hecha en su momento por el autor, el CGAC editó una serie de catálogos y diferentes textos que perpetuaron el recuerdo de la exposición y que, en realidad, completan el proyecto de la misma. «Compostela» se articulaba a partir de diez proyectos individuales de artistas que comparten un marcado interés por la reflexión sobre lo cotidiano y referencias al paisaje natural o humano, a las arquitecturas urbanas, a los monumentos o a los barrios periféricos; pero también a los aspectos más difíciles de simbolizar como la fisonomía (espiritual, sentimental, anímica) de la ciudad. Todos ellos tienen en común el uso de la imagen, en especial a través de la fotografía y el vídeo. Trabajan con Santiago como materia prima y seleccionan una visión limitada y perceptiva, subjetiva de la ciudad en función de sus intereses, proporcionando diferentes estereotipos, reunidos en una sola exposición. Una mirada alternativa de Santiago que formaba parte del programa cultural del Xacobeo 2004. La imagen promocional institucional utiliza de la cultura, y esta a su vez crea una visión de la ciudad, una imagen artística que, finalmente, retroactiva a la primera.

Esta exposición, y sus publicaciones, nos permiten acercarnos a las últimas tendencias aplicadas al paisaje urbano y humano de una ciudad. Son diez pequeñas muestras que de forma conjunta acaban ofreciendo una visión global sobre Santiago de diferentes artistas y con un carácter internacional. Sirven como un complemento necesario a la imagen de la ciudad que cada visitante se forja en su mente durante su estancia en la misma (Estévez, 2004). Aunque sea una exposición colectiva con un tema común, las representaciones artísticas de la ciudad de los participantes son formal y temáticamente muy variadas. Coinciden, sin embargo, en limitar su mirada sobre Santiago a ciertos aspectos subjetivos con la excepción de la norteamericana Simpson que aporta una obra en vídeo, titulada «Corridor», sobre el feminismo, el racismo y las relaciones sociales, ambientada en espacios fuera de la ciudad (Fernández-Cid y Gili, 2004). Y con un carácter también difícil de identificar con Compostela aparece la obra del sueco Arrhenius «The street». Reduce la ciudad a una animación pictográfica hecha por ordenador donde a través del abstracto refleja su ritmo cotidiano. Una estética que, en cierta medida, nos recuerda los esquemas de nuestra Cronogeografía o los modelos espacio-temporales de Kevin Lynch (1975).

Los otros ocho artistas poseen imágenes mucho más identificables de forma directa con Santiago y su paisaje. Quizás sea la obra del argentino Rivas la que se reduce más que ninguna otra a identificar Compostela con su centro histórico, y así el nombre de su trabajo es simplemente «Santiago». Los hitos del espacio considerado Patrimonio de la Humanidad inspiran su obra fotográfica. La arquitectura histórica se utiliza para aportar una visión sentimental del conjunto pétreo del casco histórico de la ciudad. Dentro de él, como en la imagen de marca de Compostela, la Catedral y su entorno aportan la visión principal. Una representación artística que en nada se diferencia de la turística y promocional de Santiago, salvo en la riqueza y la estética peculiar de las imágenes. 
También las calles y los monumentos del centro histórico de Santiago recrean buena parte de los proyectos de los suizos Wüthrich, llamado «Biblioteca América-Ánxos de Compostela», y Streuli, «Praza de Galicia. Agosto 03 I-III». El primero (Fig. 5) es una muestra fotográfica centrada en la Biblioteca América de la Universidad y en diferentes espacios de la ciudad, sobre todo de su casco antiguo, donde el libro y la persona son protagonistas. El libro es tratado como un objeto y aporta un símbolo cultural a las postales más reconocibles de la urbe. La cultura y el patrimonio arquitectónico se funden en la imagen artística de este autor. Streuli también utiliza el centro histórico como fondo de su obra, en este caso en vídeo-arte. En concreto, la Porta da Mámoa es el fondo donde captura a las personas que confluyen en ese nodo. La presencia humana en este espacio urbano proporciona una poderosa imagen de vida. Una visión subjetiva y muy seleccionada de Santiago que vuelve a unirse al centro histórico, en este lugar que se corresponde con una de las antiguas entradas a la Compostela amurallada. Aborda la ciudad con su propia historia y ciudadanía local (Fernández-Cid y Volk, 2004).

Figura 5

FOTOGRAFÍA DE WÜTHRICH EN LA PORTADA DE LA REVISTA «VIVE COMPOSTELA», NNo 1 (2004)

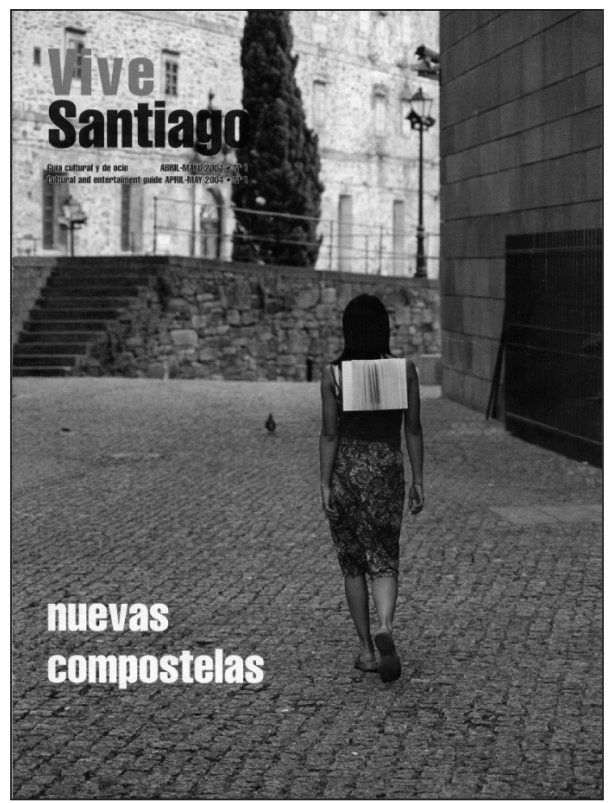

Utilizando también la fotografía está la obra del compostelano Ramos. Este artista aprovecha su condición de vecino de Santiago para ofrecernos una visión fragmentada a través de diez propuestas presentadas mediante imágenes de exposiciones prolongadas tomadas con cámaras artesanales. En un intento por apresar la vida urbana, la imagen artística de Compostela se funde aquí en una sucesión de luces, colores y texturas. Un encuentro de imágenes, de ecos de historias vividas, donde Santiago aparece como una ciudad habitada por las huellas de sus historias (Fernández-Cid y Ruiz de Samaniego, 2004). En este caso los 
espacios físicos del núcleo, tal vez por el conocimiento del autor, son más extensos, no solo el centro histórico; pero la imagen estética, un estereotipo muy positivo, es la misma que la que desprendían las piedras patrimoniales en los ejemplos anteriores.

En una combinación de artes podemos finalmente agrupar las obras de los otros cuatro artistas participantes: el italiano Basilico, los alemanes Fischer y Förg y la barcelonesa Soto. Todos ellos recurren al paisaje arquitectónico para representar un determinado Santiago, combinando aquí las referencias al centro histórico con una visión más funcional de la urbe como espacio terciarizado (y solo en algunos casos, como área residencial). Imágenes seleccionadas que vuelven a crear particulares percepciones de la ciudad. El primero, Basilico, en «Fuoricentro», supone una notable excepción a la construcción de la imagen pública de Santiago pues este autor va a mirar más allá del estereotipo Compostela. Propone una interesante mirada de la ciudad a través de numerosas fotos de los diferentes barrios periféricos, de su arquitectura de vida y de su realidad existencial (Fig. 6). El autor se olvida de la urbe monumental para centrarse en las otras, las ciudades invisibles en vez de la histórico-simbólica (Esparza y Fernández-Cid, 2004). Una visión que se queda en minoritaria, no obstante, por el poder de la imagen pública compostelana que no deja hueco para estas prácticas de la ciudad cotidiana. Igualmente, la catalana Soto, también de forma heterodoxa, refleja una representación de la ciudad con escenarios paisajísticos industriales, como las torres de comunicación del Monte Pedroso, aunque combina estás imágenes con ilustraciones de espacios extraños a la ciudad (Fernández-Cid y Miró, 2004).

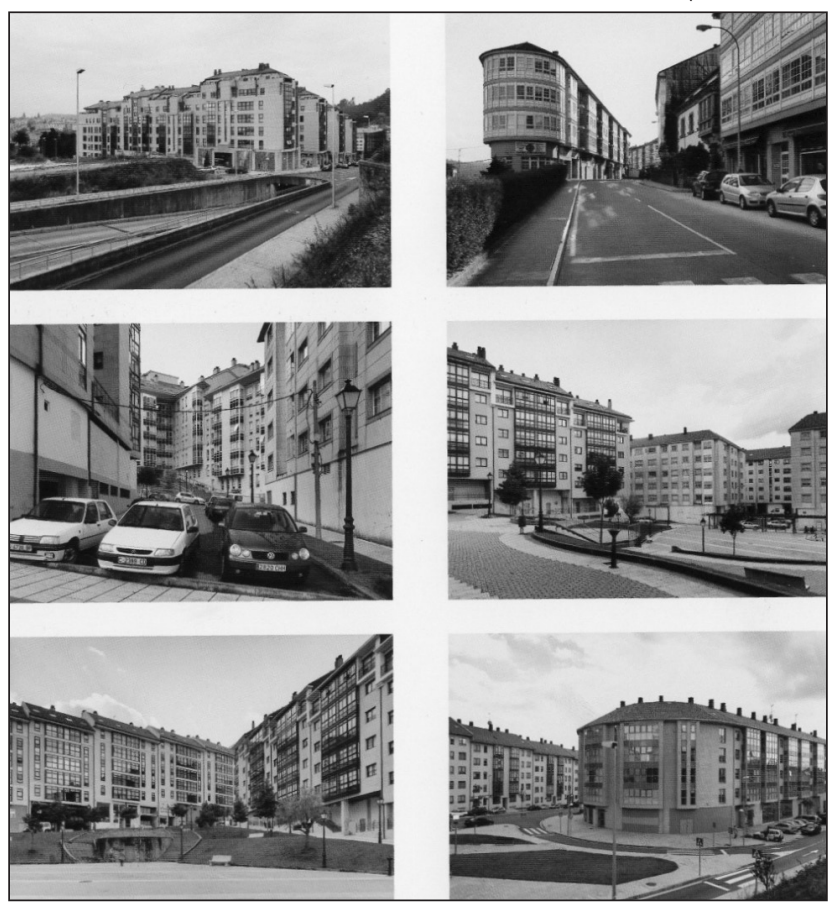


Por último, los fotógrafos alemanes Fischer y Förg se fijan en la arquitectura compostelana. Representan la ciudad a través de un reducido número de edificios emblemáticos, destacando los realizados por el prestigioso arquitecto portugués Álvaro Siza. Fischer ya había realizado una exposición individual en el CGAC («Camino», 30/9-7/12, 2003) donde reflexionaba sobre el Camino y su meta a través de sus monumentos (Ledo, 2003); una imagen histórica-patrimonial que nos es conocida. Ahora suma a esta representación una reflexión arquitectónica contemporánea, completando su homenaje a la morfología simbólica compostelana. Lo mismo hace Förg con diferentes fotografías de la Facultad de Ciencias de la Comunicación realizada por Siza (Fernández-Cid y Fuchs, 2004). La nueva arquitectura estrella, recurso patrimonial explotado en el actual marketing urbano, se combina con la funcionalidad universitaria de la ciudad en la imagen de este autor.

Dentro de la representación artística de la ciudad es de especial interés su imagen literaria. Las novelas y las obras literarias en general se convierten en una importante fuente geográfica. Se trata de analizar la visión perceptiva del artista, de captar las sensaciones que el mismo nos quiere transmitir (García Ballesteros, 1992). Sin embargo, el uso de esta fuente cualitativa para el estudio del espacio subjetivo de Santiago conlleva la enorme dificultad del extraordinario número de obras que, de un modo u otro, toman como referencia a la ciudad. Con motivo de la promoción de Compostela de la mano del Camino, los organismos públicos se preocuparon por recopilar la literatura de Santiago, sobre todo en relación con la ruta. Ya en el año 1993 el Centro Servidor de Datos de la Sociedad Anónima de Gestión del Plan Xacobeo acumulaba un total de 1.586 títulos entre libros, artículos, reportajes y otros tipos de publicaciones en gallego, castellano, francés, inglés, alemán, italiano y japonés (Celeiro, 1994). La temática de los títulos recogidos incluye guías de los Caminos de Santiago, estudios históricos, geográficos o artísticos, ensayos, novelas y poesía. Ese mismo año se celebraba una exposición de libros de la Ruta Jacobea en el Museo de la Ciudad de Madrid compuesta por más de mil volúmenes. Un último ejemplo, la Bibliografía del Camino de Santiago editada por la Subdirección General de Información y Publicaciones del entonces denominado Ministerio de Educación, Cultura y Deporte recoge en dos tomos más de siete mil citas bibliográficas. Ante esta disponibilidad de fuentes cualquier estudio de la imagen literaria de Santiago tendría difícil reflejar todo lo escrito sobre la ciudad. Tampoco es esta nuestra intención, sino aportar a las diferentes visiones subjetivas ya analizadas algunas notas sobre esta imagen de la literatura. Para tales fines es suficiente con una selección de algunos textos basados en Compostela, aunque a la fuerza incompleta.

La historia de la literatura compostelana y su propia imagen en las letras escritas nace en el interior del medieval Códex Calixtinus. El clérigo Aymeric Picaud escribió hacia el año 1140 una especie de guía del Camino de Santiago, incluida en el libro V del Códex Calixtinus, también llamado Liber Sancti Jacobi. En él, ya realizaba un pormenorizado estudio de la Ruta Jacobea, con una visión muy particular, y nada favorable por cierto, de los pueblos ibéricos que atravesaban el Camino. Utilizaba para ello gran cantidad de detalles anecdóticos, descripciones de pueblos, avisos de peligros, etcétera, que actualmente son el mejor testimonio para el estudio de aquel periodo histórico, tal y como podemos ver en la obra de Ruiz Montejo (2004). Así empieza el códice describiendo a la ciudad: «La ciudad de Compostela está situada entre dos ríos llamados Sar y Sarela. El Sar se encuentra al oriente entre el Monte del Gozo y la ciudad, y el Sarela al poniente. Las entradas y puertas 
de la ciudad son siete. La primera entrada se llama Puerta Francesa; la segunda, Puerta de la Peña; la tercera, Puerta de Sofrades; la cuarta, Puerta del Santo Peregrino; la quinta, Puerta Falguera, que conduce a Padrón; la sexta, Puerta de Susannis; y la séptima, Puerta de Mazarelos, por la que llega el precioso licor de Baco a la ciudad» (Liber Sancti Jacobi, 1998). Y de este modo se refiere a su hito principal, la basílica: «En esta iglesia no hay grieta ni defecto alguno; está magníficamente construida, es grande, espaciosa, luminosa, armoniosa, bien proporcionada en anchura, longitud y altura, y de admirable e inefable fábrica. Además, tiene doble planta como un palacio real. Quien recorre por arriba las naves del triforio, aunque suba triste, se vuelve alegre y gozoso al contemplar la espléndida belleza del templo» (Ibíd.).

Ya con mucha posterioridad, con el resurgimiento de la literatura gallega en el siglo XIX, Santiago ocupa las páginas de muchos autores de entonces. Es suficiente con recordar en la memoria alguna poesía de la poeta romántica compostelana Rosalía de $\mathrm{Castro}^{2}$, como versos de su obra Follas Novas (Castro, 1994):
¡Adiós!, montes y prados, iglesias y campanas
¡Adiós!, Sar y Sarela, cubiertos de enramada
¡Adiós!, Vidán alegre, molinos y hondonadas
Conxo, el del claustro triste y las soledades plácidas
San Lorenzo, el escondido, cual un nido entre las ramas
Belvís, para mí siempre el de los profundos recuerdos
Santo Domingo, donde cuanto quise descansa
vidas de mi vida, pedazos de mis entrañas.

En la primera mitad del siglo XX las figuras de Castelao, Vicente Risco, Ramón Otero Pedrayo (estudiado por Piñeira y Santomil, 2009) y tantos otros aportan diferentes miradas sobre Santiago en sus importantes obras. Escogemos como ejemplo al poeta, novelista y periodista ligeramente posterior Álvaro Cunqueiro y su obra Por el camino de las peregrinaciones (edición de 2004), donde recrea la imagen del Camino y de Santiago como meta, un espacio histórico de profundo significado cultural y religioso. Cunqueiro, junto al fotógrafo Magar, cubrió el trayecto entre Pedrafita y Santiago en el año 1962 reivindicando las bondades del peregrinar por la que entonces distaba mucho de ser la exitosa ruta turística de nuestros días, ya que el Camino permanecía casi en el olvido. El libro es una crónica de sus avatares, rico en detalles y anécdotas, que transcurre por las iglesias, tumbas, imágenes y frescos de la ruta. En la edición reciente se le añade un epígrafe donde se recogen artículos que Cunqueiro entregó puntualmente cada 25 de julio entre 1951 y 1974 al periódico «Faro de Vigo» (ya entonces la imagen mediática construía un estereotipo sobre Santiago). Con la especial técnica de este autor, mezclando siempre leyenda y realidad, se forma una hermosa imagen del Camino y de la ciudad de Santiago, llena de simbolismo. Una representación literaria que anticipa la difusión promocional de Compostela en la actualidad.

2 En Versos a Compostela (2011) se reúnen los poemas de Rosalía en los que la ciudad de Santiago es referente lírico. 
Centrándonos en la literatura contemporánea más actual no encontramos páginas tan brillantes como las descritas pero sí una imagen literaria de hoy, comparable pues con las otras representaciones subjetivas coetáneas. En las publicaciones más recientes acercarse a Santiago en la literatura es tratar casi repetidamente del Camino. Compostela aporta su casco histórico, sus calles y, sobre todo, su hito catedralicio a los libros que encontramos en la sección de novedades de las librerías, sean o no de ficción. Si, por ejemplo, acudimos a libros de ensayos encontraremos obras que giran sobre el Camino, Santiago y sus significados como las de Atienza (2004), Cobreros (2004), García Costoya (2004), Peradejordi (2003) o Sánchez Dragó (2004). Signos, mitos, ritos, leyendas, templos, filosofías, interpretaciones, interrogantes... ocupan estos ejemplos de literatura sobre el Camino y Compostela, con antecedentes en obras anteriores como la de Coelho (de 1988, edición de 2007). Un envolvente mundo que da una aureola mágica y misteriosa a la ciudad que toma el nombre del Apóstol, con palabras como estas que cogemos prestadas de la obra de Cobreros (2004): «La dimensión cósmica del Camino de Santiago hace del mismo una realidad acorde con el orden natural de las cosas, y, como todas las realidades dispuestas según este orden, se trata de una realidad totalizadora capaz de comunicar con las tres dimensiones de la estructura antropológica del hombre: cuerpo, alma y espíritu», o estas otras de la de Sánchez Dragó (2004) «repican otra vez las campanas de la catedral de Compostela. Los golpes de sus badajos son tan sonoros que me alcanzan incluso aquí, en el mínimo y remoto islote del océano Pacífico que me proporciona la quietud, el silencio, la serenidad, la soledad y la lejanía sin las cuales no podría seguir viviendo, creciendo, muriendo ni escribiendo».

$\mathrm{Al}$ mundo literario actual también pertenecen esas novelas que muchas veces son consideradas como menores por parte de la crítica, pero que acaban siendo los libros de mayor difusión, los más vendidos o, como el término inglés que los define dice, best sellers. En este tipo de literatura encontramos igualmente referencias a Santiago, por ejemplo en un género de moda en la actualidad como es la novela histórica de suspense. Así, podemos encontrar una Compostela medieval recreada en historias de ficción de éxito como las escritas por Matilde Asensi (2000 y 2004), Pedro Jesús Fernández (1999), Ángeles de Irisarri (2010), Paloma Sánchez-Garnica (2010) o Ulrike Schweikert (2009). Asensi, por ejemplo, en títulos latinos como Iacobus y Peregrinatio nos traslada a un Santiago medieval, tan falso o hiperreal como el que se vende en la imagen promocional. En realidad, el Camino y el centro histórico es el marco referencial de todas estas obras, como también lo es en la del propio compostelano Suso de Toro, Trece campanadas (2002). Una obra que fue galardonada con el Premio Nacional de Narrativa 2003, concedido por el Ministerio de Educación, Cultura y Deporte. Aborda una trama de corte fantástico y de terror psicológico ambientada en la ciudad, siendo, además, una indagación sobre la memoria de Compostela. Las calles y plazas del centro histórico forman el escenario urbano donde se mezcla presente y pasado, partiendo de los monumentos religiosos y de sus campanas, que dan título a la obra.

El éxito de esta última novela hizo que fuera adaptada al cine por el director gallego Xabier Villaverde, contando con subvenciones públicas, entre las cuales destacan fondos de la promoción del Xacobeo y de la ciudad de Santiago. En la película, los escenarios literarios se traducen en imágenes donde podemos reconocer la ciudad histórica compostelana. Una imagen literaria y cinematográfica nuevamente basada en el espacio Patrimonio de la Humanidad más que en el conjunto real de la ciudad. En el año Xacobeo 2010, se recurre también 
a la producción cinematográfica para la promoción del Camino de Santiago y de Compostela con la película «The Way» (El Camino), cuyo reclamo principal es el conocido actor norteamericano Martin Sheen. Pero el Santiago histórico, el Camino, la religiosidad y todos los estereotipos de su imagen pública se vienen repitiendo en el cine, por remontarnos un poco más hacia el pasado, desde El Pórtico de la Gloria de Rafael J. Salvia (1953) o la brillante La Vía Láctea (1969) de Luis Buñuel a comedias recientes como la española Al final del Camino de Roberto Santiago (2009) o la francesa Peregrinos de Coline Serreau (2005) ${ }^{3}$.

La imagen literaria y la cinematográfica conforman una misma imagen pública históricopatrimonial de Compostela, la que atrae al visitante y la que esta ciudad utiliza en la cruenta competencia urbana de la globalización.

\section{CONCLUSIÓN: LA IMAGEN PÚBLICA DE SANTIAGO DE COMPOSTELA}

Una ciudad es un espacio público, y por ello espectacular y escénico, en constante crecimiento material, que se corresponde con la creación de apreciaciones y de estimaciones que legitiman las tomas de decisión y las acciones concretas (Gil, 1994). De esta manera, los espacios urbanos fuertemente valorados se convierten en garantes sensitivos tanto de asignaciones de ideas como de intervenciones. El centro histórico compostelano y, secundariamente, las diferentes áreas dedicadas al ocio y la cultura así como a las funciones urbanas de prestigio gozan de este significado gracias a que la imagen pública de la ciudad se basa en estos caracteres. El olvido y la minimización de la problemática social y de la realidad urbana de sectores que también forman parte de Santiago, aquellos en los cuales reside la mayor parte de su población, es el crédito que se dilapida en el proceso de creación de la imagen de la ciudad. Se construye un estereotipo que se particulariza espacial y temáticamente para crear una imagen de marca de Compostela como capital cultural, funcional, promocional y turística (como también sucede en otras ciudades patrimoniales y monumentales como demostró Galí (2005) en Girona, con una imagen basada exclusivamente en su barri antic y con el río Onyar como frontera).

Una serie de iniciativas positivas, e incluso modélicas, de potenciación de imagen de la ciudad entendiéndola como una urbe histórica dieron lugar a este estereotipo en el caso compostelano. Desde los medios de comunicación de masas y desde los diferentes agentes urbanos se promueve el casco antiguo como centro cultural vinculado a la potenciación del turismo cultural y a la recuperación más o menos obligada de lo que fue un camino de peregrinación europeo. Se defienden los valores estéticos y arquitectónicos que conserva el centro histórico. En la actualidad el patrimonio cultural se manifiesta como uno de los factores de calidad más indiscutibles desde el punto de vista nacional e internacional, sobre todo si está inscrito en la lista del Patrimonio Mundial (Bernal, 2000, p. 39).

La imagen mediática, la imagen promocional y la imagen artística de la ciudad construyen una representación pública, aquella que está compartida por el conjunto de la sociedad tal y como explicábamos en el apartado 1.1. del artículo, donde demostrábamos teóricamente

3 Fuera de nuestro análisis académico, recomendamos al lector el visionado del episodio centrado en el camino del film Galatasaray-Depor de Hannes Stöhr (2005) o de la película francesa Saint-Jacques... La Mecque (2005). 
como se trata de una imagen socialmente impuesta, colectivamente aceptada o, por lo menos, generalmente tolerada (Boira, 1992b). Una imagen que en Santiago de Compostela, más que en otras ciudades, y dentro de un feroz mercado de competencia entre los núcleos urbanos para el reparto de prestigio mediático, la atracción de visitantes y la creación de la mejor representación posible, origina una marca muy concreta: Compostela. Una marca que, como cualquier otra, tiene sus logotipos y sus campañas publicitarias, los cuales, en este caso, se inspiran en hitos de la ciudad como su centro histórico o, dentro de él, la Catedral y la Plaza del Obradoiro. La prensa, la televisión, la radio, Internet, las medidas promocionales públicas y privadas, las iniciativas culturales, las guías turísticas, la obra de los artistas, el cine y la literatura mantienen el denominador común de esta imagen; y con ello sitúan la postal de la Catedral, la referencia al Apóstol y a la ciudad de piedra de origen medieval en nuestras mentes (tal vez al tiempo que el lector repara en estas palabras le venga a la suya alguna de estas representaciones) para identificar a Santiago.

Los habitantes pueden llegar a sentirse marginados en su propia ciudad ante la gran afluencia de turistas y ante la masificación de las actividades de ocio y cultura que se realizan en su interior. Además, la conversión de determinados espacios en lugares turísticos puede convertir áreas como el centro histórico, actualmente aún un espacio de vida y convivencia, en sitios paisajísticos de apropiación estacional. De la urbe vivida, la que experimentan directamente sus ciudadanos desde que se levantan hasta el final de la jornada, queda muy poco en la imagen pública de Santiago. El éxito de la imagen compostelana, la que atrae a cientos de miles de visitantes, se cobra el precio de ignorar su propia vida, de volcarse en la funcionalidad turística y patrimonial, y despreciar su condición de poblamiento humano.

Santiago no solo es la ciudad del peregrino, ni la capital donde se celebran constantemente actividades culturales y de ocio y, desde luego, no se reduce a su condición de meta del Camino. Es también, entre otras cosas, el lugar de vida de miles de estudiantes universitarios, la capital administrativa autonómica gallega, un centro sanitario de primer orden, un espacio en construcción como cualquier otra ciudad y la cabecera comarcal de una extensa área donde la agricultura y la ganadería siguen siendo importantes y donde hay una fuerte localización industrial y de empresas terciarias. Estas funciones urbanas proporcionan experiencias y sentimientos, percepciones, ajenos a los correspondientes a la imagen pública santiaguesa. Además, la propia funcionalidad turística sobredimensionada puede dar lugar a graves problemas de sostenibilidad en espacios frágiles como los centros históricos (Troitiño, 2007).

Sin embargo, aunque el sentido de lugar de cada santiagués participe de estos otros espacios de vida, el peso de la marca de Compostela supera las percepciones individuales. Sirva de ejemplo el estudio perceptivo realizado con un conjunto de estudiantes universitarios (Fumega, 1993), jóvenes que entre aulas, bibliotecas, fotocopiadoras y espacios de ocio estudiantil no siguen el ritmo delimitado por el Xacobeo, pero que señalaban al centro histórico como el espacio vivido más positivo y a la Catedral como el hito que mejor condensaba el espíritu y la identidad de Santiago y representaban siempre el casco antiguo en sus mapas mentales en una escala mayor a la real y en una localización más privilegiada que la que ocupa verdaderamente en el plano (Ibíd.). Si buscamos en los medios de comunicación de masas la percepción de los visitantes de la ciudad (las entrevistas a peregrinos y turistas, anó- 
nimos o conocidos, son muy frecuentes) la identificación del conjunto urbano con la parte histórica de Santiago es aún más unidireccional.

En definitiva, una marca, una imagen pública, la de Compostela, establece un espacio subjetivo, de percepción y de vida, de fuerte carga simbólica y con una difusión excepcional por la notable capacidad demostrada por la urbe para su promoción. Este estereotipo delimita la representación pública de la ciudad, y así López (2010, p. 44) nos demuestra que en Italia Santiago es identificada como una ciudad religiosa, un lugar sagrado conocido por ser destino del Camino o por la Catedral (hecho que la propia autora califica como un simulacro, que no se corresponde con la realidad-Ibíd., p. 46). En una sociedad donde la imagen supera a la propia realidad, Santiago de Compostela se construye en la mente del ciudadano y del visitante a través de sus hitos, de su Patrimonio, de su historia y de su funcionalidad cultural y turística.

\section{BIBLIOGRAFÍA}

ALONSO OTERO, F. (2009): «Santiago y los caminos de Santiago: un paisaje cultural, una cultura del paisaje». Boletín de la Asociación de Geógrafos Españoles, n 51, pp. 203218.

AMENDOLA, G. (2000): La ciudad postmoderna. Madrid. Editorial Celeste.

ANGUITA JAÉN, J.M. (2004): El Camino de Santiago. Guía práctica del peregrino. León. Editorial Everest.

ANTÓN CLAVE, S. (2011): Innovación territorial y modelos de desarrollo en destinos turísticos litorales. Análisis a diferentes escalas espaciales. En Seminario Red Temática de los Espacios Urbanos ante los Cambios Turísticos. Palma de Mallorca. Ponencia oral.

ASENSI, M. (2000) Iacobus. Barcelona. Editorial Plaza \& Janés.

ASENSI, M. (2004): Peregrinatio. Barcelona. Editorial Planeta.

ATIENZA, J. G. (2004): Los peregrinos del Camino de Santiago. Madrid. Editorial Edaf.

AYERBE, J.; FERIA, J.M. y JOAQUÍN, J. (2000): Atlas de Andalucía. Sevilla. Editorial de la Junta de Andalucía.

AZÚA, F. de et al. (2004): La arquitectura de la no-ciudad. Pamplona. Editorial de la Universidad Pública de Navarra.

BENACH, N. (2000): «Nuevos espacios de consumo y construcción de imagen de la ciudad en Barcelona». Estudios Geográficos, n 238, pp. 189-206.

BERNAL SANTAOLALLA, B. (2000): «Los recursos culturales de la ciudad y las políticas de desarrollo urbano» en Oportunidades de desarrollo sostenible para los conjuntos urbanos históricos (Bernal, B., Dir.). Burgos. Ediciones de la Universidad de Burgos, pp. 29-61.

BOIRA MAIQUES, J.V. (1992): «El estudio del espacio subjetivo (Geografía de la Percepción y del Comportamiento): una contribución al estado de la cuestión». Estudios Geográficos, Tomo LIII, n 209, pp. 573-592.

BOIRA MAIQUES, J.V. (1992b): La ciudad de Valencia y su imagen pública. Valencia. Ediciones de la Universitat de València.

BOIRA MAIQUES, J.V. (1996): «Planeamiento sin percepción, educación sin participación» en Actas de las II Jornadas de Geografía Urbana. Alicante. Editorial de la Universidad de Alicante, pp. 229-240. 
BOIRA MAIQUES, J.V. y CRESPO BERNI, A. (1989): «L'estudi d'un component de la formació de la imatge: la prensa local diària. El cas de la ciutat de València». Cuadernos de Geografía, n 46, pp. 169-96.

BOUZAS CAMAÑO, P. y DOMELO VILLAR, X.A. (2004): Santiago de Compostela. Y después del abrazo al santo, ¿qué?. Madrid. Editorial Martínez Roca.

BRAUNFELS, W. (1987): Urbanismo occidental. Madrid. Editorial Alianza.

CAMPESINO FERNÁNDEZ, A.J. (2000): «El patrimonio estrella del siglo XXI en las viejas ciudades históricas. La competitividad cultural» en Ciudades históricas: conservación y desarrollo. Encuentros sobre patrimonio (Castillo Oreja, M. Á, Ed.). Madrid. Fundación Argentaria, pp. 35-44.

CAMPILLO BESSES, X. (1989): «Geografía i literatura a l'alt Pirineu català: bases per a un mètode de treball humanístic a partir de la literatura». Documents d'Anàlisi Geogràfica, $\mathrm{n}^{\mathrm{o}} 15$, pp. 111-122.

CAPÓN GARCÍA, J.L. y GARCÍA OROSA, B. (2004): «Las bitácoras o weblogs y la lógica del campo informativo. Un análisis comparativo con la agenda mediática tradicional». Estudios sobre el Mensaje Periodístico, nº 10, pp. 113-128.

CASTRO, R. de (1994): Follas Novas=Hojas Nuevas. Madrid. Editorial Akal.

CASTRO, R. de (2011): Versos a Compostela. Santiago de Compostela. Editorial Alvarellos.

CEJUDO CÓRDOBA, R. et al. (2005): «Tipologías de ciudad: imágenes y secuencias urbanas en el cómic europeo» en La ciudad: ausencia y presencia (Román, R, Coord.). Córdoba. Editorial Plurabelle, pp. 107-132.

CELEIRO ÁlVAREZ, L. (Dir.) (1994): Xacobeo 93. Santiago de Compostela. Edición de la Xunta de Galicia.

COBREROS, J. (2004): Camino de Santiago, geografía del espíritu. Barcelona. Editorial Obelisco.

COELHO, P. (2007): El peregrino de Compostela (Diario de un mago). Barcelona. Editorial Planeta.

COSTA, J. (1992): Imagen pública. Una ingeniería social. Madrid. Editorial Fundesco.

COSTA MAS, J. (2009): «Los paisajes urbanos en sus representaciones fílmicas. Una aproximación desde la Geografía Humanística» en Geografía, Territorio y Paisaje: el estado de la cuestión: actas del XXI Congreso de Geógrafos Españoles (Pillet, F. et al., Coords.). Cuenca. Editorial de la Universidad de Castilla-La Mancha y Asociación de Geógrafos Españoles, pp. 885-897.

CUNQUEIRO, Á. (2004): Por el camino de las peregrinaciones. Barcelona. Editorial Alba.

ESCUDERO GÓMEZ, L.A. (1997): «La prensa diaria, un elemento de análisis para las Ciencias Sociales: Aplicaciones en Geografía Urbana». Revista Antropológicas, $\mathrm{n}^{\circ}$ 1, pp. 91-100.

ESCUDERO GÓMEZ, L.A. (2000): La imagen de A Coruña, Santiago de Compostela y Ferrol a través de la prensa diaria: Estudio de Geografía de la Percepción. Santiago de Compostela. Ediciones de la Universidad de Santiago de Compostela. [Cd-rom]

ESCUDERO GÓMEZ, L.A. (2007): «Los nuevos medios de creación de imagen de las ciudades ibéricas Patrimonio de la Humanidad: páginas Web en Internet» en Actas del X Coloquio Ibérico A Geografía Ibérica no contexto europeu. Évora. Editorial de la Universidade de Évora. [Cd-rom] 
ESPARZA, R. y FERNÁNDEZ-CID, M. (2004): Gabriele Basilico. Santiago de Compostela. Ediciones del Centro Gallego de Arte Contemporáneo.

ESTÉBANEZ ÁLVAREZ, J. (1982): Tendencias y problemática actual de la Geografía. Madrid. Editorial Cincel.

ESTÉVEZ, X. L. (2004): «Nuevas miradas sobre Compostela». Revista Vive Santiago, 2004, $\mathrm{n}^{\mathrm{o}} 1$, p. 4.

FERNÁNDEZ-CID, M. y FUCHS, R. (2004): Günther Förg. Santiago de Compostela. Ediciones del CGAC.

FERNÁNDEZ-CID, M. y GILI, M. (2004): Lorna Simpson. Santiago de Compostela. Ediciones del CGAC.

FERNÁNDEZ-CID, M. y MIRÓ, N. (2004): Montserrat Soto. Santiago de Compostela. Ediciones del CGAC.

FERNÁNDEZ-CID, M. y RUIZ DE SAMANIEGO, A. (2004): Rubén Ramos Balsa. Santiago de Compostela. Ediciones del CGAC.

FERNÁNDEZ-CID, M. y VOLK, G. (2004): Beat Streuli. Santiago de Compostela. Ediciones del CGAC.

FERNÁNDEZ MARTínEZ, P. J. (1999): Peón de rey. Madrid. Editorial Alfaguara.

FORMIGO COUCEIRO, X. y LOIS GONZÁLEZ, R. C. (2000): Santiago de Compostela. Vive y Descubre. León. Editorial Everest.

FUMEGA PIÑEIRO, F.X. (1993): Vivencias geográficas compostelanas: geografía de la percepción y del comportamiento. Santiago de Compostela. Editorial Tórculo.

GALÍ ESPELT, N. (2005): La imatge turística del patrimoni monumental de Girona. Girona. Universitat de Girona.

GÁMIR, A. y VALDÉS, C. M. (2007): «Cine y geografía: espacio geográfico, paisaje y territorio en las producciones cinematográficas». Boletín de la Asociación de Geógrafos Españoles, $\mathrm{n}^{\circ} 45$, pp. 157-190.

GARCÍA BALLESTEROS, A. (Dir.) (1992): Geografía y Humanismo. Barcelona. Editorial Oikos-Tau.

GARCÍA COSTOYA, C. (2004): El misterio del apóstol Santiago. Mito y realidad. Barcelona. Editorial Plaza \& Janés.

GIL DE ARRIBA, C. (1994): Las representaciones socio-espaciales y la producción de la imagen de la ciudad de Santander, siglos XIX y XX. Santander. Universidad de Cantabria. [Microforma]

GIL DE ARRIBA, C. (2002): Ciudad e imagen. Un estudio geográfico sobre las representaciones sociales del espacio urbano de Santander. Santander. Editorial de la Universidad de Cantabria.

GOMIS, L. (1991): Teoría del Periodismo. Como se forma el presente. Barcelona. Editorial Paidos.

GONZÁlEZ TIEMBLO, Á. (2004): El Camino de Santiago por la Costa o Camino Norte. León. Editorial Everest.

HALL, P. (2000): «La redefinición de las ciudades europeas» en Ciudades intermedias: urbanización y sostenibilidad (Bellet, C. y Llop, J.M., Eds.). Lleida. Editorial Milenio, pp. 391-401. 
HARVEY, D. (1998): La condición de la posmodernidad. Investigación sobre los orígenes del cambio cultural. Buenos Aires. Editorial Amorrortu.

HERÉTER, R. (1998): Aeroguía del Camino Santiago. La ruta jacobea vista desde el cielo. Barcelona. Editorial Planeta.

HERNÁNDEZ RAMÍREZ, J. (2004): «Turismo inducido. La configuración de la imagen turística de Sevilla a través del cine comercial» en Actas del I Congreso Internacional Patrimonio, Desarrollo rural en el Siglo XXI. Osuna. Escuela Universitaria de Osuna. http://www.eurosuna.org

IRISARRI, A. de (2010): La estrella peregrina: una peregrinación a Santiago de Compostela en el año mil. Madrid. Editorial Suma de Letras.

LARA VALLE, J.J. (2002): «El patrimonio urbano del siglo XXI: Políticas y estrategias sobre el patrimonio integral urbano» en Turismo y transformaciones urbanas en el siglo XXI (Asensio Hita, A.; Fernández Gutiérrez, F. y Pumares Fernández, P., Eds.). Almería. Ediciones de la Universidad de Almería, pp. 399-433.

LEDO, A. (Coord.) (2003): Roland Fischer. Camino. Santiago de Compostela. Ediciones del CGAC.

LEDO, A. (Coord.) (1998): Liber Sancti Jacobi: Códex Calixtinus. Santiago de Compostela. Edición de la Xunta de Galicia.

LOIS GONZÁLEZ, R. C. (1999): «El geógrafo urbano ante la crisis actual» en La ciudad. Tamaño y crecimiento (Domínguez Rodríguez, R., Coord.). Málaga. Ediciones de la Universidad de Málaga, pp. 499-509.

LÓPEZ, L. (2010): La ciudad y su imagen turística. El caso de Santiago de Compostela en el mercado turístico italiano. Santiago de Compostela. Idega.

LYNCH, K. (1975): ¿De qué tiempo es este lugar? Para una nueva definición del ambiente. Barcelona. Editorial Gustavo Gili.

LYON, D. (1997): Postmodernidad. Madrid. Editorial Alianza.

MOLINA COLLADO, A. (2005): Análisis de imagen y utilidad generada por los folletos de información turística. Toledo. CES.

MONCADA, A. (1991): El nuevo poder informativo en España. Multimedia, multinacionales y multinegocios. Madrid. Ediciones Libertarias.

NADAL, P. (2003): El camino de Santiago a pie. Madrid. Editorial El País Aguilar.

PAÜL AGUSTÍ, D. (2007): «Fòrum Barcelona 2004: una visión de las transformación urbana a través de la prensa» en AA.VV.: Los procesos urbanos postfordistas. Palma de Mallorca. Editorial de la Universitat de les Illes Balears.

PERADEJORDI SALAZAR, J. (2003): Símbolos fundamentales del Camino de Santiago. Barcelona. Editorial Obelisco.

PICORNELL CLADERA, M. et al. (2009): La platja de Palma. Pautes per a una reconversió integral $i$ sostenible. Palma de Mallorca. INESE.

PIÑEIRA MANTIÑÁN, M. J. y SANTOMIL MOSQUERA, D. (2009): «Marketing territorial y paisaje natural en Galicia», en Geografía, Territorio y Paisaje: el estado de la cuestión. Actas del XXI Congreso de Geógrafos Españoles (Pillet, F. et al., Coords.). Cuenca. Universidad de Castilla-La Mancha y Asociación de Geógrafos Españoles, pp. 557-572.

POMBO, A. (2004): El Camino de Santiago. Guía del peregrino. Madrid Anaya. Touring Club. 
PONCE HERRERO, G.; DÁVILA LINARES, J.M. y NAVALÓN GARCÍA, M.R. (1994): Análisis urbano de Petrer: Estructura urbana y ciudad percibida. Alicante. Ediciones de la Universidad de Alicante.

RIVERO, T. y SERRA. T. (2002): La sociedad de la información y la ciudad. Barcelona. Editorial Metrópolis.

RUIZ MONTEJO, I. (2004): El camino a Santiago. Andares de un peregrino en la España del siglo XII. Madrid. Editorial Foca.

SÁNCHEZ DRAGÓ, F. (2004): Historia mágica del Camino de Santiago. Barcelona. Editorial Planeta.

SÁNCHEZ-GARNICA, P. (2010): El alma de las piedras. Barcelona. Editorial Planeta.

SANTOS SOLLA, X.M. (Coord.) (2005): Galicia en cartel: A imaxe de Galicia na cartelaría turística. Santiago. Universidade de Santiago de Compostela.

SOBRINO MANZANARES, M.L. (2005): «Sobre carteis e a historia da arte» en Galicia en cartel: A imaxe de Galicia na cartelaría turística (Santos, X. M., Coord.). Santiago. Universidade de Santiago de Compostela, pp. 47-52.

SCHWEIKERT, U. (2009): La maldición del Camino de Santiago. Barcelona. Editorial Plaza.

SEIXAS SEOANE, M. A. (1998): Santiago y Galicia. Mérida. Editorial Límite Visual.

TORO, S. de (2002): Trece badaladas. Santiago de Compostela. Edicións Xerais de Galicia. TORRENTE BALLESTER, G. (1948): Compostela. Madrid. Editorial Afrodisio Aguado.

TROITIÑO VINUESA, M.A. (1995): «El turismo en las ciudades historicas». Polígonos. Revista de Geografía, n ${ }^{\circ}$ 5, pp. 49-65.

TROITIÑO VINUESA, M.A. (2007): «Estrategias Sostenibles en Destinos Patrimoniales: De la Promoción a la gestión integrada e innovadora». Estudios Turísticos, nº 172-173, pp. 225-232.

TUDURÍ BORRAS, C. (1998): Turismo, imagen promocional y comunicación. El caso particular de La imagen de Mallorca em La prensa britânica. Barcelona. Editorial de La Universitat Autònoma de Barcelona.

VAN DIJK, T.A. (1990): La noticia como discurso. Barcelona. Ediciones Paidos.

ZÁRATE MARTÍN, A. (1995): «Los medios audiovisuales en la enseñanza de la Geografía» en Enseñar la Geografía. De la teoría a la práctica (Marrón, M ${ }^{\mathrm{a}} \mathrm{J}$. y Moreno, A., eds.). Madrid. Editorial Síntesis, pp. 239-275.

ZOIDO NARANJO, F. et al. (2000): Diccionario de geografía urbana, urbanismo y ordenación del territorio. Barcelona. Editorial Ariel.

ZUNZUNEGUI DÍEZ, S. (1989): Pensar la imagen. Madrid. Editorial Cátedra.

\section{Páginas web consultadas en diversas fechas a lo largo del año 2011:}

- Arzobispado de Santiago de Compostela. <http://www.archicompostela.org>

- Ayuntamiento de Santiago de Compostela. <http://www.santiagodecompostela.org>

- Cámara de Comercio de Santiago de Compostela. <http://camaracompostela.com>

- Catedral de Santiago de Compostela. <http://catedraldesantiago.es>

- Compostela Virtual. <http://www.compostelavirtual.com>

- Costasur. <http://santiago-de-compostela.costasur.com> 
- Galinor. <http://www.galinor.es/santiago>

- Google. <http://www.google.es>

- Instituto Gallego de Estadística. <http://www.ige.eu>

- Santiago de Compostela por Todo Sobre España <http://red2000.com/spain/ santiago/1santia.html >

- Universidad de Santiago de Compostela. <http://www.usc.es>

- Wikipedia. < http://es.wikipedia.org/wiki/Santiago_de_Compostela> 